\title{
PSYCHOLOGICAL ASSESSMENT IN HUMAN RESOURCES MANAGEMENT: CHARACTERISTICS, BIASES AND SOLUTIONS
}

\author{
Riccardo Sartori, University of Verona, Verona, Italy \\ Andrea Ceschi, University of Verona, Verona, Italy \\ Ksenia Dorofeeva, University of Verona, Verona, Italy \\ Massimo Bellotto, University of Verona, Verona, Italy
}

dx.doi.org/10.18374/EJM-13-2.6

\begin{abstract}
Over the last five years, researchers in psychology and social sciences (Taleb, 2007; Mlodinow, 2008; Sartori and Ceschi, 2011, 2012; Sartori and Rolandi, 2012) have strongly stressed what classical studies by famous Tversky and Kahneman among the others found in the Sixties or Seventies (Tversky and Kahneman, 1974; Kahneman, 1991): psychological assessment is a very delicate issue because of the quantity and the quality of information assessors have to manage. One of the reasons for stressing this concept again and again is the increase over years of psychological assessment activities. For example, assessment and development centers are procedures applied to professional, business and organizational contexts in order to assess employeesâ $\epsilon^{\mathrm{TM}}$ potential according to career development. They are forms of psychological assessment making use of different methods and techniques, some (i.e. interviews) descending from the so called idiographic (or clinical) approach, and some (i.e. standardized instruments) descending from the so called nomothetic (or psychometric) approach. Different methods and techniques are believed to be necessary for assessors and decision makers in order to let them collect as much information as possible and come to an integrated judgment of people to be evaluated for human resources management. This is common sense, though, and it is hard to make assessors understand that the more the information collected, the higher the difficulties to manage it and to distinguish between relevant and irrelevant information, with the result that assessment and decision making activities carried out in this way can be biased. Given these remarks, the article aims to be a brief critical review of what psychological science has found in the field of assessment, in the hope that people dealing with human resources management become aware of the risks related to gathering too much information for assessment purposes.
\end{abstract}

Keywords: Psychological Assessment; Human Resources Management; Biases 